\title{
GÉNESIS Y EVOLUCIÓN DEL FENÓMENO URBANO EN EL TERRITORIO ONUBENSE
}

\section{ORIGINS AND EVOLUTION OF URBANISM IN THE HUELVA TERRITORY}

\author{
por \\ JUAN M. CAMPOS CARRASCO
}

RESUMEN

En este trabajo, dedicado al prof. D. Manuel Pellicer, se dan a conocer los resultados de varios proyectos de investigación orientados hacia el análisis de la implantación y evolución del fenómeno urbano en el territorio onubense desde sus inicios hasta época medieval. El estudio, que se basa fundamentalmente en el análisis de los enclaves de Niebla, Huelva y San Mamés (Aroche), establece los orígenes de este fenómeno en el Bronce Final Prefenicio, recibiendo un gran impulso con fenicios y púnicos hasta cristalizar de forma definitiva con la romanización.

\begin{abstract}
Devoted to Prof. Pellicer, this paper summarizes the evidences obtained in several research proyects conducted to explain the implantation and development of urban phenomena in the Huelva province, as from its beginning to medieval period. Based on archaeological analysis of Niebla, Huelva and the San Mamés (Aroche) roman site, the origins of urban phenomena in the pre-phoenician Late Bronze is stablished, reckoning an important impact due to phoenician and punic influences until it definitevely chrystallized with romanization.
\end{abstract}

Palabras claves Fenómeno Urbano. Bronce Final-Edad Media. Huelva. Andalucía Occidental.

Key words Urban Phenomena. Late Broze-Middle Age. Huelva. Western Andalucia

\section{INTRODUCCIÓN}

El fenómeno urbano, en sentido amplio, es un tema que aparece ampliamente tratado en la literatura arqueológica europea, abordándose desde la perspectiva de comprender nuestra historia pasada en función de la aparición del urbanismo, de su génesis y evolución. 
Desde esta visión se han realizado numerosos estudios en la Península Ibérica centrados de forma preferencial en las grandes áreas culturales en detrimento del análisis de áreas periféricas o marginales donde a nuestro entender pueden encontrarse.importantes respuestas para comprender la génesis del fenómeno urbano.

En general existe una divergenćia en cuanto a las opiniones formuladas sobre este fenómeno cuya aparición se ha ido retrasando cronológicamente, según las distintas opiniones, hasta situarlo, en opinión de algunas corrientes de investigación (Bendala 1989), entre las que nos encontramos (Campos y Gómez 1995), en un momento anterior a la colonización fenicia.

En Andalucía, ha sido el bajo Guadalquivir el que ha aglutinado la mayoría de estos estudios, al ser el área cultural más activa durante época orientalizante y de la Bética romana. Sin embargo, el área atlántica, es decir el territorio onubense, está aportando una serie de indicadores que han revalorizado extraordinariamente el papel que éste territorio, en principio considerado marginal, jugó en la génesis del fenómeno urbano, como consecuencia entre otros factores de la concentración de las minas de la Franja Ibérica de Piritas al norte de este territorio.

Descendiendo a las zonas arqueológicas donde hemos centrado especialmente nuestro análisis, como son San Mamés (Aroche) en la Sierra de Huelva; Tejada la Nueva, Niebla y Huelva en la Tierra Llana, indicar que hasta fines de los ochenta habían recibido un desigual tratamiento arqueológico, aunque en todo caso, hemos de señalar como nota característica, salvo en los dos últimos asentamientos citados, la falta de globalidad en los objetivos que han orientado las distintas intervenciones.

Ni que decir tiene que no se ha realizado ningún trabajo tendente a integrar y valorar espacialmente el área comprendida por el área de influencia de los citados yacimientos a lo largo de sus respectivas secuencias (cronoestratigráficas) culturales, ni abordado el estudio desde la perspectiva de analizar el proceso de implantación de las ciudades.

Hasta tal punto eran inexistentes los estudios sobre la implantación urbana en el territorio onubense que incluso para el período romano apenas se habían realizado investigaciones hasta los trabajos que en los últimos años venimos realizando desde el Área de Arqueología de la Universidad de Huelva (Vidal 2001). El desconocimiento que sobre el proceso de la romanización en este lugar un tanto periférico de la Bética y su significación en el proceso histórico de la zona se tenía, se traducía en hechos tales como la dificultad para poder identificar ciudades que aparecen citadas en las fuentes grecolatinas, y que hasta hace menos de una década sólo en algunos casos - Onoba (Huelva), Ilipla (Niebla) e Iptuci (Tejada la Nueva)- había sido posible. Sólo en los últimos años se han identificado el resto de las ciudades: Ostur (Mesa del Castillo), Turobriga (San Mamés), Arucci (Fuente Seca) y Urium (Riotinto).

Con esta perspectiva, iniciamos, en 1990 en la Tierra Llana, un proyecto de amplio espectro cronológico y cultural bajo el título "Dinámica de Asentamientos y Evolución de Sistemas Naturales: la Secuencia Holocena del Litoral y Prelitoral entre el Guadiana y el Guadalquivir", cuyo objetivo global fue explicar las claves generales de la población del territorio de forma diacrónica y su vinculación al proceso evolutivo del paisaje cultural y natural (Campos, Castiñeira, García y Borja 1991). En los 5 años de desarrollo del mismo (1990-94), que generaron cerca de una veintena de publicaciones y una monografía final (Campos y Gómez 2001), se pudo establecer una primera aproximación a la secuencia físico-cultural holocena de litorales y campiñas, a la vez que se realizó un primer ensayo de unidades naturales y territoriales, donde se detectaron una serie de problemas históricos que requerían ser analizados desde proyectos específicos y en marcos territoriales más definidos.

Sin duda, es el marco territorial de la campiña, el que se muestra como el de más alta concentración del poblamiento y consecuentemente afectado por una fuerte antropización cifrada especialmente en la implantación desde antiguo de una serie de núcleos urbanos y en el desmantelamiento de las formaciones vegetales.

Cumpliendo pues con la filosofía inicial del proyecto antes citado, donde se preveía abordar desde proyectos específicos problemáticas muy concretas, desarrollamos un nuevo proyecto que se centró en la investigación de un problema histórico específico en un marco cronológico y territorial de ámbito mucho más reducido. 
El objetivo general que pretendimos alcanzar con esta investigación fue el análisis de la implantación y evolución del fenómeno urbano en las campiñas onubenses, eligiendo de este modo un marco considerado como marginal dentro de la investigación histórica del suroeste hispano y que había sido objeto de muy pocas investigaciones en el tema que nos proponíamos tratar.

Para cubrir el objetivo final propuesto, consideramos imprescindible, con independencia del análisis del territorio y de los asentamientos urbanos concretos, centrar los esfuerzos de manera prioritaria en un yacimiento donde fuera posible analizar el fenómeno urbano desde sus inicios hasta la Edad Media y donde pudiera ponerse en práctica una estrategia de investigación que permitiera el análisis global de los diferentes aspectos que caracterizan el nacimiento de la ciudad. Sin duda, es Niebla, junto con Huelva, la que reúne las mejores condiciones en todo el ámbito del suroeste hispano al oeste del Guadalquivir. Nace así el proyecto de Arqueología urbana de la Ciudad de Niebla (PAUCN) financiado por la Consejería de Cultura de la Junta de Andalucía.

A partir de 1997 decidimos crear un marco organizativo de más amplia cobertura para el desarrollo de esta línea de investigación presentando, en 1997 al Plan Nacional de I+D, un proyecto específico sobre mundo urbano que fue aprobado con vigencia, en su primera fase, hasta el año 2000 (Análisis de la implantación y evolución del fenómeno urbano en el SO peninsular: las campiñas onubenses. PB96-1496). La incorporación a nuestras investigaciones de los yacimientos de Turobriga (San Mamés, Aroche) donde hemos realizado excavaciones en el foro para solucionar problemas de conservación, y Huelva de la que hemos realizado la Carta del Riesgo, junto con la aprobación de una segunda fase del proyecto del Ministerio de Ciencia y tecnología para los años 2001-2003 (BHA2000-1347) nos han permitido abarcar el total del territorio onubense.

\section{ASPECTOS METODOLÓGICOS}

Es importante resaltar la contrastación de la metodología utilizada en el análisis del territorio ampliamente expuesta en los proyectos. La aplicación del método ha permitido un alto conocimiento de un territorio, que aunque prospectado con anterioridad por otros equipos, carecía de un catálogo significativo de yacimientos que permitiera abordar análisis como el que nos planteamos con un cierto grado de fiabilidad.

A escala microespacial, se tiene un exhaustivo análisis de los enclaves de mayor significación que se distribuyen en el territorio. Se ha prestado especial atención a aquellos que presentan rasgos urbanos en algún momento de su discurrir, tal es el caso de Tejada la Vieja, Tejada la Nueva, Aznalcóllar, Mesa del castillo y sobre todo Huelva Niebla y San Mamés, a los que posteriormente nos referiremos. En todos ellos se han realizado prospecciones microespaciales con amplia documentación y recogida controlada de materiales; actividad que también se hizo extensiva a otros enclaves de alto rango como Cerro de la Matanza, La Atalayuela, etc.

Especial atención se ha prestado, como ya se ha indicado, en los casos de Huelva Niebla y San Mamés, pues con independencia del análisis del territorio y de los asentamientos urbanos concretos, era necesario centrar los esfuerzos de manera prioritaria en algún yacimiento donde fuera posible analizar el fenómeno urbano desde sus inicios hasta la Edad Media y donde pudiera ponerse en práctica una estrategia de investigación que permitiera el análisis global de los diferentes aspectos que caracterizan el nacimiento de la ciudad. Para ello los enclaves de Niebla, Huelva y San Mamés, reúnen las mejores condiciones en todo el ámbito del suroeste hispano al oeste del Guadalquivir. Durante el desarrollo de los proyectos se han realizado varias excavaciones que han permitido definir el papel desempeñado por los asentamientos de Huelva y Niebla en la configuración de un modelo de ciudad con orígenes en el Bronce Final y su evolución a lo largo de las etapas prerromana, romana y medieval, explicando el rango que el concepto urbano ha tenido a lo largo de este periodo en la campiña de Huelva, analizando las causas que provocan los distintos modelos por la interacción de relaciones económicas y sociales entre mundo urbano y su territorio. Por otra 
parte, las excavaciones en la ciudad romana de Turobriga (San Mamés, Aroche), han permitido conocer el proceso de incorporación de los ámbitos serranos al mundo urbano.

\section{ORIGEN Y EVOLUCIÓN DEL FENÓMENO URBANO}

Las investigaciones citadas han permitido obtener un notable volumen de evidencias que refuerza nuestra hipótesis, planteada hace casi una década en el Congreso de Jerez de 1993 (Campos y Gómez 1995), acerca de los orígenes del fenómeno urbano en el Bronce Final prefenicio. Como se ha indicado anteriormente, ha sido el análisis de los núcleos más significativo de la Tierra Llana los que han aportado nuevas evidencias.

La ubicación de Niebla en la rica campiña onubense y en un vado del río Tinto, que procede del área minera del Andévalo (Cinturón Ibérico de Piritas) y la de Huelva en el estuario de los ríos Tinto-Odiel, fueron los factores que determinaron el surgimiento de estas ciudades y han favorecido su mantenimiento, aun cuando alguno de estos recursos perdieron valor. Los inicios del asentamiento permanente en los cascos urbanos de Huelva y Niebla, en los comienzos del I milenio a.C., están íntimamente relacionados con el auge que vive en estos momentos la producción de cobre y plata en el Andévalo y la necesidad de dar curso a esta producción a través del enclave portuario onubense. La función de puerto atlántico de Huelva y la posterior vocación agrícola de Niebla convierten, sin duda, a estos asentamientos en los más importantes de la provincia de Huelva para el estudio de la evolución y desarrollo del fenómeno urbano.

De capital importancia será el laboreo de minerales de cobre y de plata en Riotinto a partir de mediados del II milenio a.C. (Pérez 1996), lo que va desencadenar, cuando se establezcan circuitos mediterráneos de este metal, el surgimiento de núcleos centrales desde los que se controlan los mismos, como son los casos de Aznalcóllar, Niebla y Huelva. Ésta será la etapa, ya en los comienzos del I milenio a.C., en la que Niebla pasa a desempeñar un papel destacable en el control del territorio, lo que obligará al establecimiento estable en la meseta donde se asienta, que será el verdadero origen de la ciudad según los registros arqueológicos excavados (Campos 1996).

El aspecto urbanístico de estos núcleos, asentamientos centrales de este territorio que marcaron el ritmo del comercio de minerales de plata desde la zona minera del Cinturón Ibérico de Piritas, Riotinto y Aznalcóllar principalmente, hacia la Ría de Huelva, debió ser, con las diferencias impuestas por la topografía, muy similar. El recinto amurallado se circunscribe a las zonas altas, extendiéndose el resto del hábitat por las más bajas.

En estos momentos asistimos, pues, a un impulso renovador que cristaliza en la gestación de modelos de ocupación de clara inspiración urbana, que conllevan la jerarquización del territorio, diferenciación de fronteras, control exclusivo de determinados recursos y acumulación de excedentes, que puede influir en la vinculación de asentamientos subordinados, la revitalización de las redes comerciales regionales que, a su vez, por medio del comercio marítimo podían interrelacionarse tanto con el Atlántico como con el Mediterráneo, debido a su posición entre ambos circuitos comerciales de la Edad del Bronce.

Es evidente, pues, que en la Tierra Llana de Huelva, antes de la presencia de los fenicios en la costa atlántica andaluza, existía una sociedad compleja y dinámica que había alcanzado por sus propios medios una estructura territorial conceptualmente urbana, la cual será aprovechada por los orientales que, simplemente, se integrarán en ella (Gómez y Campos e.p.). A la llegada de los fenicios no todos los asentamientos occidentales eran poblados de cabañas diseminados en el territorio (Gómez 1997), por el contrario, algunos, en función de su posición y del aprovechamiento de los recursos locales, muestran una clara diferencia observable en su tamaño y en la estructura funcional de su espacio habitado que se caracteriza por la pronta construcción de murallas desde fines del siglo VIII a. C. y principios del siglo VII a.C., bien documentadas en estos asentamientos. Durante los siglos VII, al final del cual se dotará a Tejada la Vieja de murallas, VI y V a.C., lejos de lo creído hasta ahora, los núcleos de la Tierra Llana presentan una gran actividad constructiva de modo que su aspecto urbanístico se va consolidando (Gómez 1997; Pérez, Campos y Gómez 2000; Gómez y Campos 2000 y 2001; Campos y Gómez 2001). 
Un importante aspecto a resaltar en el desarrollo del fenómeno urbano es la influencia púnico-gaditana, primero, y Bárcida, después, en estos enclaves. En Niebla hemos documentado niveles de incendio de fines del siglo III a.C. (Beltrán 2001), cuya explicación más plausible es relacionarlos con la $2^{\mathrm{a}}$ Guerra Púnica y la ofensiva final romana sobre las ciudades aliadas de los Cartagineses. En las excavaciones predominan en estos niveles de incendio ánforas púnicas características del Círculo del Estrecho (De Frutos y Muñoz 1994), una prueba de la intensa relación comercial con Gadir. Es precisamente en época bárquida en la que se asiste a la activación de la zona miera de Riotinto que retoma el pulso de la explotación de época Orientalizante (Pérez 1996), y no es extraño por ello que Niebla volviera a ocupar el papel de cabeza de puente en la comercialización de la misma. Esta presencia púnica está también adquiriendo notoriedad en los últimos estudios que estamos realizando sobre el enclave de Huelva (Gómez y Campos 2001) y está también presente en el ámbito serrano donde se detectan contactos de los celtici de la Baeturia Celtica con el mundo púnico-gaditano (Campos, Vidal y Pérez 2000).

Son pues muchos los indicios que sugieren una intensa influencia púnica ligada a los intereses comerciales de Gadir. Se cree incluso que este sustrato púnico, de comprobada tradición urbana y extensión en la Turdetania (Bendala 1987), es el que facilitaría posteriormente, en época romana, la adopción de fórmulas religiosas plenamente urbanas, las características de las élites municipales y coloniales, el culto al emperador y a las divinidades oficiales (Júpiter, Juno y Minerva), bien atestiguadas en la zona de Onoba, Ilipla e Iptuci desde época temprana (Oria 1999). Las dedicatorias a Juno en Ostur, como hipóstasis de Dea Caelestis (Tanit), y las espigas de las monedas de Ilipla, símbolo de Tanit, pueden obedecer a este mismo ambiente cultural. No obstante, y a pesar de destacar la influencia púnica como elemento decisivo en la configuración de algunas de estas ciudades, en la consolidación de las élites urbanas desde época prerromana como factor que propiciará el proceso de municipalización posterior y del programa ideológico que estaba detrás del mismo, conviene señalar también que este nuevo proceso que finaliza con el cambio de estatuto jurídico a municipium se aceleraría especialmente con el asentamiento de poblaciones ciudadanas en la zona desde época augústea, en un comienzo de repartos de tierras que no está estudiado todavía.

La proyección estética de la política augústea sobre las ciudades hispanas tuvo su principal reflejo en la potenciación de los lugares públicos, donde se hacía evidente la intensificación de la función programática y política de los elementos constructivos y decorativos. Ello tuvo como principal consecuencia la génesis de grandes cambios que cambiaron la faz de los núcleos urbanos que existían antes de la llegada de Roma, así como una modelización para los de nueva creación. Se hace patente pues, la importancia concebida a la arquitectura como elemento de referencia funcional pero también como instrumento ideológico y político de primer orden (Abad y Bendala 1996). En todo este proceso será, lógicamente, el foro, como ámbito principal de la vida pública, el elemento donde más intensamente se ejecutará la propaganda política de Roma y del Emperador, con lo que de nuevo se observa cómo la ciudad se convierte en un instrumento de fijación y comunicación de la ideología patrocinada por el princeps (Zanker 1987). Una vez instalado el modelo, los sucesores de Augusto, tanto de su propia dinastía-los Julio-Claudios-, como de las siguientes-Flavios y Antoninos-, no harán sino mantenerlo con las lógicas modificaciones derivadas de las necesidades y planteamientos de cada momento, y como ejemplo contamos con un testimonio de la mayor importancia en la ciudad de Turobriga en el Norte de la provincia (Campos, Vidal y Pérez 2000), territorio que no se incorporará hasta estos momentos a la vida plenamente urbana.

Pero la municipalización general de Hispania después de la extensión del ius latii en tiempos de Vespasiano, ensombrece a nuestro modo de ver una evolución más compleja que el simple cambio generalizado a partir de época flavia. Ya algunos autores han desdeñado este "fetichismo flavio", y si se ahonda en este contexto se aprecia que al menos en el Oeste peninsular se privilegió a poblaciones que ya lo estaban reclamando, pues la presencia de estas poblaciones ciudadanas iniciaron el camino a la municipalización. Este hecho, señalado ya para Portugal (Alarçao 1990), puede explicarse también en nuestra zona. En primer lugar porque las poblaciones ciudadanas asumen desde el cambio de Era los hábitos de las élites municipales, el evergetismo 
y la plena identificación ideológica con el estado romano, bien sea de la mano del culto al emperador, bien de prácticas religiosas con el panteón oficial romano, como ya se ha apuntado, en un intento por obtener beneficios con esta conducta más que por propia inducción de la política romana (Alvar 1999).

Son estas mismas poblaciones ciudadanas las que a lo largo de la etapa julio-claudia, especialmente en tiempos de Nerón, se identifican con el culto dinástico, como puede comprobarse por la dedicación de estatuas de Julia Agrippina (Del Amo 1976 y 1980), y marcan el rumbo de la civitas. No es por eso extraño que el programa de monumentalización, de adecuación de la estructura urbana de la ciudad al mundo romano, comience en estos momentos.

Algo diferente sería la situación en la zona serrana donde no existían núcleos urbanos previos, como en la Tierra Llana, y donde desde la II ${ }^{a}$ Edad del Hierro se asientan poblaciones procedentes de la Meseta, los Celtici de la Baeturia celtica (García 1971). Estas poblaciones, diferentes de los Turdetanos de la Tierra Llana, que, como ya se indicó, también mantuvieron contactos con el mundo púnico-gaditano y con las poblaciones turdetanas, fueron más reacias a la conquista y a la romanización, que sólo comenzará cuando en los enfrentamientos civiles en Hispania estos pueblos participen en alguno de los bandos, y cuando esos bandos, para identificarse con las poblaciones célticas, respeten y adopten algunas de sus costumbres (Campos, Vidal y Pérez 2000).

Las fuentes de la época no detallan, sin embargo, la participación de estas poblaciones en este último episodio de las Guerras Civiles, pero los hechos que sucedieron en el período inmediatamente posterior transparentan una especial sensibilidad de la política cesariana por toda la comarca betúrica. No pueden comprenderse de otro modo los cognomina de la gens Iulia de la mayoría de los oppida de la Baeturia, Nertobriga Concordia Iulia, Lacimurga Constantia Iulia, Segida Restituta Iulia, etc. No existe un acuerdo unánime sobre su significación jurídica (Marín 1988; Cortijo 1993), pero no nos cabe duda de que como recompensa muchos de estos oppida dejarían de ser civitates stipendiariae, bien recibiendo algún tipo de inmunitas o accediendo a la categoría de municipium, como es evidente en el Municipium Iulium Ugultaniacum (Fernández 1988). No deja de ser sorprendente que poblaciones con bajo nivel de romanización recibieran esta titulatura antes que otros núcleos que deberían estar más romanizados, como aquellos de la Tierra Llana de Huelva que lo reciben en época flavia, que desde hacía más de un siglo vivían plenamente incorporados en el orbe político y económico romano.

Es aquí donde a nuestro juicio interviene otro factor de romanización, la avalancha de población latina, que en muchos lugares acabaría imponiéndose a la población indígena. Estas poblaciones de inmigrantes, que vemos perfectamente integradas en las civitates a comienzos del siglo I d.C., debieron incorporarse a las mismas a lo largo del siglo I a.C., unas veces como asentamientos de veteranos tras los períodos de luchas, otras como poblaciones relacionadas con las societates publicanorum que iniciaron la exploración y explotación sistemática de los cotos mineros del Suroeste. Estas gentes de origen latino acabarían por formar y capitalizar los ordines decuriorum de los municipia en la segunda mitad del siglo I d. C. A partir de este momento Baebii, Vibii, Sempronii, etc se hacen corrientes en la epigrafía latina de la zona (González 1989).

La importancia de la ciudad romana no entrará en crisis hasta el s. IV cuando se detecta en nuestro territorio un proceso de ruralización. En la Tierra Llana, la explotación agrícola de las villas rústicas se extiende por todo tipo de suelos, sobre las terrazas de grava y arena del río Tinto, sobre los limos arenosos del Pliocuaternario, y en la ribera del Tinto, donde muchas de estas villas cumplirían a la vez la función de embarcaderos, hacia donde debería itinerar la producción de explotaciones colindantes. Como ocurre en el Guadalquivir, en estos puertos fluviales hemos detectado también figlinae para la fabricación de los envases necesarios en la comercialización, especialmente dolia, tal como se aprecia en los testares que aún se conservan. Otros alfares se sitúan en villas más alejadas del río. Estas villas rústicas alcanzaron su período de máxima eclosión en el siglo IV d.C., síntoma de la reactivación económica que se produjo en este siglo después de las reformas de Diocleciano y posterior gobierno de la dinastía constantinea. Este registro, único hasta ahora en toda la provincia, marca el tránsito a época visigoda y emiral, y estaría señalando 
la continuidad de las formas de explotación rural romana en los siglos VI y VII d.C., en los que el papel administrativo de Niebla se acentuó con la creación de la sede episcopal, sufragánea de la de Sevilla, como cabecera de distrito de la mayor parte de la provincia de Huelva, y que será, en último extremo, de capital importancia para la configuración islámica de la Kura de Niebla.

Además de esta continuidad en el poblamiento en época visigoda, otro de los yacimientos detectados, Los Bojeos, nos informa sobre la vocación rural de la nobleza hispanovisigoda, al aparecer la lápida funeraria que nos indica el enterramiento de un obispo en el ámbito rural y no en el urbano (Pérez, Campos y Gómez 2000).

En resumen, por los datos que manejamos puede constatarse la pérdida de importancia del espacio urbano, pero no así del mundo rural, que desde el punto de vista administrativo y religioso parece asumir funciones antes desempeñadas por las élites urbanas. Es decir, la cristalización de un proceso de ruralización que iniciado con seguridad en las villas rurales en el siglo IV d.C., terminará por liquidar el esquema de implantación urbana que se consolidó con la propia Romanización.

No será hasta los siglos IX y X d. C. cuando se retorne al protagonismo de lo urbano sobre lo rural, cuestión que se detecta perfectamente en las murallas de Niebla que como elemento simbólico vuelve a ocupar la atención de sus habitantes que la someten a una importante reforma.

\section{CONCLUSIONES}

En el estado actual de los conocimientos, podemos afirmar que el proceso urbano en el territorio onubense es el fruto de un largo desarrollo que comienza en los inicios del I milenio a. C. en el Bronce Final prefenicio, pudiendo estar en la base del mismo un proceso de evolución local influido por las relaciones cada vez más evidente con el Mediterráneo desde el II milenio, toda vez que como ya han señalado otros autores (Bendala 1989) el mundo atlántico no presentaba en estos momentos una estructura de corte urbano. Este proceso que se precipita con la llegada de los fenicios, tendrá un gran impulso tras la presencia bárcida para cristalizar de forma definitiva en el mundo romano cuando a los núcleos ya habitados con anterioridad en la Tierra Llana se les añade los de Ostur e Iptuci y se da el salto al resto del territorio con los enclaves de Urium en el Andévalo y Turobriga y Arucci en el ámbito serrano.

Sólo el paréntesis que se produce a partir de los siglos IV-V d. C. representará un receso en el peso de la ciudad en el conjunto del territorio que se recuperará a partir de los siglos IX-X d. C., si bien hay que señalar que inicialmente la etapa islámica, lejos de representar una ruptura, aportó pocos cambios con relación a las ciudades romanas, salvo una mayor impronta del factor-religioso y étnico en la configuración de su estructura.

Agradecimientos. Contribución a los proyectos del Ministerio de Ciencia y Tecnología PB96-1496 y BHA2000-1347 y al Proyecto de Arqueología Urbana en la Ciudad de Niebla de la Consejería de Cultura de la Junta de Andalucía.

\section{BIBLIOGRAFÍA}

ABAD, L. y BENDALA, M. (1996): "Urbanismo y Ciudad: de las formaciones ibéricas a la consolidación del modelo romano", Actas XIII Congreso Nacional de Arqueología. Vol. II. Elche.

ALARÇÃO, J. (1990): “O dominio romano", Portugal, das origens á Romanização. Lisboa. 
JUAN M. CAMPOS CARRASCO

ALVAR EZQUERRA, J. (1999): “Arquitectura religiosa e integración social: aspectos de la romanización de la Bética", Ciudades privilegiadas en el Occidente Romano. Sevilla.

BELTRÁN, J.M. (2001): Un corte estratigráfico en el tramo de murallas del desembarcadero de Niebla (Huelva). Trabajo de Investigación de Tercer Ciclo Inédito. Universidad de Huelva.

BENDALA GALÁN, M. (1987): "De la protohistoria a la conquista romana", Historia General de España y América, I-2. Madrid.

- (1989): "La génesis de la estructura urbana en la España Antigua", CuPAUAM, 16: 127-147. Madrid.

CAMPOS CARRASCO, J.M. (1996): "Arqueología Urbana en la ciudad de Niebla (Huelva)", Jornadas Europeas de Patrimonio. Patrimonio y Ciudad. Sevilla.

CAMPOS, J.M. y GÓMEZ, F. (1995): “El territorio onubense durante el Bronce Final”, Tartessos, 25 años después. Jerez de la Frontera.

- (2001): La Tierra Llana de Huelva: Arqueología y Evolución del Paisaje. Sevilla.

CAMPOS, J.M.; CASTIÑEIRA, J.; GARCÍA, J.M. y BORJA, F. (1991): "Arqueología y evolución del paisaje. Un proyecto geoarqueológico en la Tierra Llana de Huelva", Cuadernos del Suroeste 2: 43-72. Huelva.

CAMPOS, J.M.; VIDAL, N.O. y PÉREZ, J.A. (2000): "La ciudad romana de Turobriga. Un modelo urbano en los Llanos de Aroche (Huelva)", Anales de Arqueología Cordobesa, 11.

CORTIJO CEREZO, Mª L. (1993): La administración territorial de la Bética. Córdoba.

DEFRUTOS, G. y MUÑOZ, A. (1994): "Hornos púnicos de Torre Alta (San Fernando, Cádiz)”, Arqueología en el entorno del Bajo Guadiana. Sevilla.

DEL AMO Y DE LA HERA, M. (1976): “Un retrato de J. Agripina (?)", Huelva Arqueológica II. Huelva. (1980): "Notas sobre epigrafía romana en la provincia de Huelva)", Huelva Arqueológica IV. Huelva.

FERNÁNDEZ CORRALES, J.M. (1988). El asentamiento romano en Extremadura y su análisis espacial. Cáceres.

GARCÍA IGLESIAS, J.A. (1971): “La Baeturia, un problema geográfico de la Hispania Antigua”, Archivo Español de Arqueología 44. Madrid.

GÓMEZ TOSCANO, F. (1997): El final de la Edad del Bronce entre el Guadiana y el Guadalquivir. El territorio y su ocupación. Huelva.

GÓMEZ, F. y CAMPOS, J.M. (2001): Arqueología en la Ciudad de Huelva (1966-2000).Servicio de Publicaciones de la Universidad de Huelva. Huelva.

(2000): "Arqueología urbana en Huelva. Las últimas evidencias", Anales de Arqueología Cordobesa 11. Córdoba.

- (e.p.): "El proceso urbano en la Tierra Llana de Huelva en el I Milenio a.C.", Actas del II Congreso de Estudios del próximo Oriente. Cádiz-El Puerto. 24-27 Enero, 2001.

GONZÁLEZ FERNÁNDEZ, J. (1989): Corpus de inscripciones latinas de Andalucía I: Huelva'. Sevilla. MARÍN DÍAZ, M.A. (1988): Emigración, colonización y municipalización en la Hispania republicana. Granada.

ORIA SEGURA, M. (1999): “Testimonios religiosos en las minas de Riotinto: algunas reflexiones”, Spal6. Sevilla.

PÉREZ MACÍAS. J.A. (1996): La metalurgia extractiva prerromana en Huelva. Huelva. (1998). Las minas de Huelva en la Antigüedad. Huelva.

PÉREZ, J.A.; CAMPOS, J.M. y GÓMEZ, F. (2000): "Niebla de oppidum a madina", Anales de Arqueología Cordobesa 11.

VIDAL, N. (2001): La implantación romana en el extremo occidental de la Bética. Doctrina y praxis en la ocupación del territorio onubense. Tesis doctoral inédita. Universidad de Huelva.

ZANQUER, P. (1987): Augusto y el poder de las imágenes. Madrid. 